\title{
Coactivator SRC-1 is dispensable for transcriptional control by Stat3
}

\author{
Helena CVIJIC, Kay BAUER, Dennis LÖFFLER, Gabriele PFEIFER, Conny BLUMERT, \\ Antje K. KRETZSCHMAR, Christian HENZE, Katja BROCKE-HEIDRICH, and \\ Friedemann HORN ${ }^{1}$
}

Institute of Clinical Immunology and Transfusion Medicine,

University of Leipzig, Johannisallee 30, 04103 Leipzig, Germany

Running Title: Stat3 coactivators

Key words: Acute-phase reaction, interleukin-6 (IL-6), signal transducer and activator of transcription 3 (Stat3), steroid receptor coactivator-1 (SRC-1), transcription control

${ }^{1}$ To whom correspondence should be addressed (e-mail friedemann.horn@medizin.unileipzig.de)

Abbreviations used: AD, activation domain; ACT, $\alpha_{1}$-antichymotrypsin; CARM1, coactivatorassociated arginine methyltransferase 1; CBP, CREB (cAMP-responsive element binding protein) binding protein; C/EBP $\beta$, CCAAT/enhancer binding protein- $\beta$; ChIP, chromatin immunoprecipitation; DMEM, Dulbecco's modified Eagle's Medium; EGFP, enhanced green fluorescent protein; gp, glycoprotein; GADD45 $\beta$, growth and DNA damage-inducible 45- $\beta$; HEK293, human embryonic kidney 293; IL, interleukin; IKB, inhibitor of kappa B; IRE, interferon-response element; IRF-1 interferon response factor-1; NF- $\mathrm{B}$, nuclear factor kappa $\mathrm{B}$; p/CAF, p300/CBP-associated factor; PE, phycoerythrin; PRMT1, protein arginine methyltransferase 1; shRNA, small hairpin RNA; SOCS3, suppressor of cytokine signaling 3; SRC, steroid receptor coactivator; Stat, signal transducer and activator of transcription; TRAP220, thyroid hormone receptor-associated polypeptide 220; tk, thymidine kinase 


\section{SYNOPSIS}

Steroid receptor coactivator-1 (SRC-1) has been reported to interact with and to be an essential coactivator for several members of the signal transducer and activator of transcription (STAT) family, including Stat3, the major signal transducer of interleukin-6 (IL-6). We addressed the question whether SRC-1 is crucial for IL-6- and Stat3-mediated physiological responses like myeloma cell survival and acute-phase protein induction. In fact, silencing of SRC-1 by RNA interference rapidly induced apoptosis in IL-6-dependent INA-6 human myeloma cells, comparable to what was observed upon silencing of Stat3. By chromatin immunoprecipitation at Stat 3 target regions of various genes, however, we observed constitutive binding of SRC-1 that decreased when INA- 6 cells were treated with IL-6. The same held true for Stat 3 target genes analyzed in HepG2 hepatocellular carcinoma cells. SRC-1 knock-down studies demonstrated that Stat3-controlled promoters require neither SRC-1 nor the other p160 family members SRC-2 or SRC-3 in HepG2 cells. Furthermore, microarray expression profiling demonstrated that the responsiveness of IL- 6 target genes is not affected by SRC-1 silencing. In contrast, coactivators of the CBP/p300 family proved functionally important for the transactivation potential of Stat3 and bound inducibly to Stat 3 target regions. This recruitment did not depend on the presence of SRC-1. Altogether, this suggests that functional impairment of Stat3 is not involved in the induction of myeloma cell apoptosis by SRC-1 silencing. We therefore conclude that Stat3 transactivates its target genes by the recruitment of $\mathrm{CBP} / \mathrm{p} 300$ coactivators and that this process generally does not require the contribution of SRC-1. 


\section{INTRODUCTION}

Interleukin- (IL)-6 is a multifunctional cytokine able to modulate various physiological events such as cell differentiation, proliferation, survival, and apoptosis in several organs and biological responses. As an early-response cytokine expressed during an acute inflammatory reaction, IL-6 is the major inducer of the hepatic production of most acute-phase proteins. We could identify Stat 3 as the central component of IL-6 signal transduction that is initiated through glycoprotein (gp) 130, the signal transducing subunit of the IL-6 receptor complex [1, 2]. Following binding of IL-6 to its receptor, Stat3 is recruited to phosphotyrosine motifs of gp130, becomes phosphorylated at tyrosine 705 by gp130-associated Janus kinases, and translocates to the nucleus where it binds to regulatory DNA elements of target genes [1-3]. Besides its contribution to cytokine signaling, Stat3 is also known to participate in cellular transformation and oncogenesis $[4,5]$. For an increasing number of tumor cell types, including multiple myeloma, prostate, and colon carcinoma, Stat3 has been shown to control growth and cell suryival [6].

Many studies indicate the involvement of various coactivators in the transcriptional action of Stat3 [7-10]. Coactivators act as bridging factors between DNA-bound transcription factors and the basal transcriptional machinery, recruiting additional coactivators and chromatin remodelling complexes and initiating acetylation and other modifications of nucleosomal histones as well as transcription factors. Among the first coactivators identified, CREB binding protein (CBP) as well as the highly related p300 both contain a histone acetyltransferase activity $[11,12]$. They act as common transcriptional coactivators for a number of transcription factors including STATs [8, 13]. Another intensively studied coactivator is steroid receptor coactivator- (SRC-)1 (alternative name: NCoA-1). Together with two related coactivator proteins, SRC-2 (NCoA-2, GRIP-1) and SRC-3 (p/CIP), it constitutes the p160 coactivator family [14]. SRC-1 plays a role in transcriptional activation by nuclear receptors and other transcription factors [14]. Among STAT factors, interaction with and functional importance of SRC-1 was first demonstrated for Stat6, and more recently for Stat5 and Stat3 [7, 15, 16]. Exclusive recognition of SRC-1, but not the related family members SRC-2 and SRC-3, by Stat6 was further elucidated by studying their structural features, revealing that a amphipathic, $\alpha$-helical Stat6 LXXLL motif binds to the PAS domain of SRC-1 through specific hydrophobic interactions [17, 18].

SRC-1 was reported to interact with Stat3, bind to Stat3 target promoters and to enhance the Stat3-dependent transcription of the p21 ${ }^{\text {waf }}$, junB, c-myc, and cyclin D1 genes [7, 19-21]. Furtermore, knock-down of SRC-1 in mammary carcinoma cells interfered with the leptin- and Stat3-mediated proliferative response of these cells [19, 21]. Consequently, SRC-1 was regarded an important if not essential coactivator for Stat3. Although, however, targeted disruption of the Stat3 gene in mice is known to be lethal [22] SRC-1 (-/-) mice display a phenotype correlated to thyroid hormone resistance [23] but are viable and do not seem to indicate defects in Stat3related functions. This apparent contradiction prompted us to revisit the contribution of SRC-1 to Stat3-induced transcriptional and (patho)physiological responses. As we show here, initial experiments with IL-6-dependent myeloma cells indeed demonstrated that silencing of SRC-1 expression by RNA interference caused a rapid onset of apoptosis in these cells, equivalent to the apoptosis induction when Stat3 expression was knocked down. However, we failed to observe inducible binding of SRC-1 to Stat3 target genes in myeloma cells. We hence initiated a broader study on the potential involvement of SRC-1 in the transcriptional control of Stat 3 target genes in the HepG2 hepatocellular carcinoma cell line, for which an involvement of SRC-1 had been reported. SRC-1 was required neither for the transcriptional response of Stat 3 target genes nor for the recruitment of CBP and p300 to Stat3-dependent promoters. Furthermore, microarray 
studies revealed no significant difference in IL-6 responses between normal HepG2 cells and cells depleted of SRC-1. We therefore conclude that in general, p160 family coactivators are not essential coactivators for the transactivating potential of Stat 3 and that the reported interaction between Stat3 and SRC-1 might serve other functions. 


\section{EXPERIMENTAL}

\section{Reporter and expression vectors}

The luciferase reporter vector phACT-359Luc containing the promoter region $(-359 /+25$, relative to the transcription start site) of the human $\alpha_{1}$-antichymotrypsin (ACT) gene was constructed by subcloning the promoter fragment from phACT-359CAT [24] into pGL3-Basic (Promega, Madison, USA). A 543-bp fragment of the human haptoglobin promoter was amplified by PCR from HepG2 genomic DNA and inserted into the Nhe I and Bgl II sites of pGL3-Basic. SRC-1 expression vectors were gifts from Dr. Kalkhoven (London, UK) and Dr. Edith Pfitzner (Jena, Germany), respectively. pGAL4-CBP-(1-451) and pGAL4-CBP(451-721), coding for fusion products of the respective CBP fragments and the DNA-binding domain of GAL4 were a gift of Dr. Bernhard Lüscher (Aachen, Germany). Murine Stat3 expression vector pRC/CMV-Stat3 was a gift of C. Schindler (New York). pRC/CMV-Stat3-LFAA was obtained by introducing mutations changing leucines 755 and phenylalanine 757 of Stat 3 into alanines, as described by Zhao et al. [20]. Construction of a vector encoding a Stat 3 mutant resistant to silencing by pSUPER-shStat3 (see below) was achieved by introducing silent mutations into the RNA interference target sequence by the QuikChange Site-Directed Mutagenesis Kit (Stratagene, La Jolla, CA, USA), yielding pcDNA-Stat3res. The thus mutated Stat3 region was subcloned into pRC/CMV-Stat3-LFAA yielding pRC/CMV-Stat3res-LFAA. The vector MLV-Eg/Flag/EGFP encoding the chimeric receptor Eg consisting of the erythropoietin receptor extracellular and the gp130 intracellular domains has been described previously [25].

\section{RNA interference vectors}

RNA interference target sequences for silencing SRC-1 and Stat3 expression were chosen according to guidelines for the pSUPER RNAi vector system (OligoEngine) and the most effective ones selected by verifying the reduction of protein levels. Small hairpin RNA (shRNA) expression vectors were constructed according to Brummelkamp et al. [26] in the pSUPER vector (a gift of R. Agami, Amsterdam, The Netherlands). Following 64-bp oligonucleotides were subcloned into the Bgl II and Xho I sites of pSUPER (only the sequence of the upper strands is shown; silencing target sequence and linker/loop sequences in upper and lower case, respectively): 5'-gatccccGATTTC-CAGTCATGTCTGAttcaagagaTCAGACATGACTGGAAATCtttttggaaa-3' (pSUPER-shSRC-1) and 5'-gatccccCAATCCCAAGAATGTAAACttcaagagaGTTTACATTCTTGGGATTGttttggaaa-3' (pSUPER-shStat3). A vector coding a scrambled shStat3 sequence (pSUPER-shScrambled) was generated accordingly. To silence SRC-2 and SRC-3 expression, the target sequences as selected and verified by Zhang et al. [27] were used with the same vector system. Oligonucleotides were obtained from MWG-Biotech (Ebersberg, Germany). For stably silencing SRC-1 expression in HepG2 cells, the shRNA expression cassette of pSUPER-shSRC-1 was subcloned as a 315-bp Xba I/HinD III fragment into the Xho I site of the lentiviral infection vector Vig-NEO-IRES-GFP, yielding Vig-shSRC-1. Vig-NEOIRES-GFP (containing a neomycin gene for selection and the enhanced green fluorescent protein (EGFP) gene as a marker for transduction efficiency) was generated by introducing the neomycin gene into the BamHI and SpeI sites of MLV-IRE-EGFP [25].

\section{Lentiviral infection}

Lentiviral supernatants for Vig-shSRC-1, Vig-shStat3, or Vig-shScrambled were obtained as described [25]. For lentiviral infection, $2.2 \mathrm{ml}$ supernatant were added to $7 \times 10^{5} \mathrm{HepG} 2$ cells in a $60 \times 15 \mathrm{~mm}$ tissue culture dish and incubated for 2-4 hours. After adding $2.8 \mathrm{ml}$ medium the 
incubation was continued for 2 days. The cells were then placed in fresh medium supplemented with $10 \mathrm{mg} / \mathrm{ml} \mathrm{G418} \mathrm{(geneticin,} \mathrm{Sigma-Aldrich,} \mathrm{St.} \mathrm{Louis;} \mathrm{MO,} \mathrm{USA),} \mathrm{used} \mathrm{for} \mathrm{selection} \mathrm{of}$ stable transformants. HepG2 cells infected with empty Vig-IRES vector have been used as a control. Infection efficiency was evaluated by using flow cytometry for detection of EGFP signal in infected cells in 3-day intervals starting from two days post-infection.

\section{Cell culture, transient transfection, and reporter gene assays}

Human embryonic kidney (HEK)-293 cells and human hepatocellular carcinoma cells (HepG2) were maintained in Dulbecco's modified minimal essential medium (DMEM) and a 1:1 mixtures of DMEM and Eagle's F12 (v/v), respectively, each containing $10 \%(\mathrm{v} / \mathrm{v})$ fetal calf serum with $1 \%(\mathrm{w} / \mathrm{v})$ penicillin/streptomycin (Life Technologies Gibco, Eggenstein-Leopoldshafen, Germany). Cells were transfected by the calcium phosphate co-precipitation method as described [1]. Cells were starved in serum-free medium for $24 \mathrm{~h}$ prior to $\mathrm{IL}-6$ stimulation. $48 \mathrm{~h}$ after transfection, cells were stimulated for $6 \mathrm{~h}$ with IL-6 $(10 \mathrm{ng} / \mathrm{ml})$, a gift from Dr. Stefan Rose-John (University of Kiel, Germany), and harvested. Luciferase activity was determined using the Luciferase assay system (Promega, Madison, WI) and normalized to $\beta$-galactosidase activity (Roche, Mannheim, Germany) by cotransfection of the $\beta$-galactosidase expression vector pCH110 (Amersham Biosciences, Freiburg, Germany).

Human myeloma INA-6 cells were cultivated in RPMI medium (PAA Laboratories, Pasching Austria) with $1 \mathrm{ng} / \mathrm{ml}$ IL-6, 10\% fetal calf serum (v/v) and 1\% penicillin/streptomycin $(\mathrm{w} / \mathrm{v})$. For transient transfection, INA-6 cells were harvested by centrifugation at $300 \mathrm{x} \mathrm{g}$ and resuspended in frsh RPMI medium without additives to a cell count of $1 \times 10^{7} / \mathrm{ml}$. Electroporation was performed using a GenePulserTM (Bio-Rad, Munich, Germany) and a cuvette $(0.4 \mathrm{~cm}$ electrode, gap 50, Bio-Rad) at settings of $950 \mu \mathrm{F}$ and $280 \mathrm{~V}$. For each experiment $500 \mu \mathrm{l}$ of cell suspension was used and $1.5 \mu \mathrm{g}$ pEGFP and $18.5 \mu \mathrm{g}$ pSUPER vectors. After electroporation, 500 $\mathrm{ml}$ of medium without additives were added and the cells transferred to RPMI with $20 \%$ fetal calf serum and IL-6.

\section{Immunoblots}

Cell lysis or nuclear extraction were performed as described by Bellido et al. [28] and Andrews, et al. [29], respectively. Equal amounts of total protein were separated by SDS polyacrylamide gel electrophoresis $(6 \%$ gel), blotted to polyvinyl difluoride membrane (Amersham Biosciences, Freiburg, Germany), and detected by chemiluminescence (SuperSignal West Dura Substrate; Pierce, Rockford, IL). SRC-1 monoclonal antibody was obtained from Upstate (Charlottesville, Virginia, USA). Antibodies to SRC-2/GRIP-1 and SRC-3/NcoA-3 were from Santa Cruz Biotechnology (Santa Cruz, CA, USA). Anti-phospho-Stat3 (Y705) and Stat3 monoclonal antibodies were obtained from Cell Signaling (Boston, MA, USA) and BD Transduction Laboratories (San Jose, CA, USA) respectively. ERK antibody (BD Biosciences, Heidelberg, Germany) was used to confirm equal loading.

\section{Apoptosis assay}

In INA-6 cells, apoptosis was measured using the annexin $\mathrm{V}$ apoptosis detection kit II (BD Biosciences, Heidelberg, Germany) using annexin V-phycoerythrin (PE). Flow cytometric analysis was done using a FACScan flow cytometer using the CellQuest software (BD Biosciences, Heidelberg, Germany). The analysis was restricted to successfully transfected cells by gating of EGFP-positive cells. 


\section{Chromatin immunoprecipitation (ChIP)}

Before ChIP, HepG2 cells were serum-starved for 2 days, and INA-6 cells withdrawn from IL-6 for $12 \mathrm{~h}$. After IL-6 stimulation $(10 \mathrm{ng} / \mathrm{ml})$ for $30 \mathrm{~min}$, cells $\left(1.5 \times 10^{7}\right)$ were cross-linked by addition of formaldehyde to the medium at a final concentration of $1 \%$ and incubated for $10 \mathrm{~min}$ at room temperature. ChIP was performed according to the protocol of ChIP assay kit (Upstate, Charlottesville, Virginia, USA).

The following antibodies were used for ChIP: antibodies to Stat3 were from R\&D Systems (Minneapolis, MN, USA), to SRC-1 (M-341), SRC-2/GRIP-1 (M-343), SRC-3/NcoA-3 (M397), CBP (A-22), p300 (C-20), p/CAF (H-369), thyroid-hormone receptor-associated protein 220 (TRAP220) (M-255), and RNA-polymerase II (N-20) from Santa Cruz Biotechnology (Santa Cruz, CA, USA).

The PCR primer sequence used for these experiments were: BCL3 gene intronic enhancer HS 4: sense 5'-CATTCGAGGATGGAAGTTGG-3', antisense 5'CAGGGTTAAGTGAGGGCAG-A-3'; haptoglobin promoter: 5'-GGTCATAGAGTTGCCAGGTTTC-3', 5'-TATGCTGCCACTA-GCTCACTTC-3'; junB promoter (69): 5'TAGCTTTCCTGGCGTCGTTTCC-3'， 5'-CGTG-GCCGCTGTTTACAAGG-3'; c-fos promoter, sis-induced element (SIE) region: 5'-GAACAAGGGTCCGCATTGA-3', 5'-TACAGGGAAAGGCCGTGGAA-3'; $\beta$-actin gene: 5'-CCAAGGCCAACCGCGAGAAGATGAC-3'; 5'-AGGGTACATGGTGGTGCCGCCAGAC-3'.

\section{RNA isolation and real-time PCR}

Total RNA was prepared from $5 \times 10^{6}$ cultured cells using the RNeasy Mini Kit (Qiagen, Hilden, Germany) according to the manufacturer's instructions. RNA quality was examined by the RNA 6000 LabChip Kit on a 2100 bioanalyzer (Agilent Technologies, Waldbronn, Germany). Realtime PCR detection was done with a LightCycler (Roche, Mannheim, Germany). An independently set-up GAPDH control was used to follow reaction quality of each template. PCR was carried out by Light Cycler-DNA Master SYBR Green I kit (Roche, Mannheim, Germany) according to the manufacturer's directions.

\section{Gene expression analysis by DNA-oligonucleotide arrays}

Double-stranded DNA was synthesized from total RNA, amplified as cRNA, labeled, and hybridized to Affymetrix GeneChips HG-U133A (Affymetrix, Santa Clara, CA, USA), which were washed and scanned according to procedures developed by the manufacturer. Two independent sets of experiments were performed to assess IL-6-dependent expression patterns in HepG2 and HepG2- $\triangle$ SRC1 cells. Normalization of the individual arrays based on total intensity and comparative data analysis were performed with the Affymetrix software (MicroArray Suite MAS 5.0.1/MicroDB 2.0/DMT 2.0). Significance criteria for selecting genes differentially expressed in response to IL-6 were chosen as follows: the microarrays hybridized with RNA from INA- 6 cells withdrawn from IL-6 for $12 \mathrm{~h}$ were set as reference chips which microarrays derived from INA-6 cells treated with IL-6 for 1 or $4 \mathrm{~h}$ were compared to. Genes were regarded differentially expressed if in both experimental sets the change p-values were below 0.0025 and beyond 0.9975 (signal change call I and D according to the MAS5 software) for increased and decreased probe set signal intensities, respectively. Alternatively, data analysis was carried out using the ArrayAssist software (Stratagene, La Jolla, CA, USA) employing various analysis algorithms, producing equivalent results.

\section{Microarray data}


Data obtained in this study by microarray analysis have been deposited at the Gene Expression Omnibus (GEO) database at NCBI, accession number GSE4885. 


\section{RESULTS}

\section{Silencing of SRC-1 expression induces rapid apoptosis in INA-6 myeloma cells}

Human INA-6 multiple myeloma cells are strictly dependent on IL-6 for their survival $[25,30]$. We previously demonstrated that the anti-apoptotic effect of IL-6 requires the activation of Stat3, and identified a number of target genes controlled by Stat 3 in these cells [25]. We now asked whether the coactivator SRC-1, reported to be essential for Stat3 transcriptional activity towards several genes $[7,19,20]$, is also required for blocking apoptosis in INA-6 cells. To this purpose, SRC-1 expression was silenced using a vector expressing a shRNA targeting human SRC-1 mRNA. This vector yielded an efficient down-regulation of SRC-1 protein when tested in human HEK-293 (Fig. 1A) and HepG2 cells (see below). In INA-6 cells transfected with this vector, apoptosis increased dramatically whereas a vector expressing a scrambled shRNA sequence had no effect (Fig. 1B). When compared to the onset of apoptosis observed in response to knockdown of Stat3, both extent and time course of apoptosis appeared comparable (Fig. 1C). In the view of these experiments we reasoned that the apoptotic effect of SRC-1 silencing might be due to blocking the expression of survival genes that are under the control of Stat3.

\section{SRC-1 binding to Stat 3 target gene promoters is decreased rather than increased after IL-6 stimulation in both INA-6 and HepG 2 cells}

To further substantiate this hypothesis, we investigated whether SRC-1 is recruited to Stat3 target genes in INA-6 cells along with the trancription factor in response to the cytokine as it had been shown for the $\mathrm{p} 21^{\text {waf }}$ in HepG2 hepatocellular carcinoma as well as for c-myc and cyclin D1 genes in MCF-7 mammary carcinoma cells [7, 19, 21]. Since INA-6 cells require the permanent presence of IL- 6 for survival, the cytokine was only transiently withdrawn from the medium $12 \mathrm{~h}$ before the cells were restimulated with IL-6. As we have previously shown, this period of IL-6 withdrawal still allows the cells to be rescued from apoptosis but is sufficient to entirely down-regulate Stat3 activity as well as expression of Stat3 target genes [25]. In situ binding of Stat3 and SRC-1 to promoter and enhancer regions of Stat 3 target genes was analyzed by chromatin immunoprecipitation (ChIP), Using primers specific for the well-characterized Stat3 sites in the BCL3 intronic enhancer HS4 [31] and the promoter of the junB gene (Fig. 2, upper panel), we could demonstrate inducible binding of Stat3 to both elements. Unexpectedly, however, binding of SRC-1 was evident even in untreated cells and decreased - rather than increased - in response to IL-6.

Given the reported inducible recruitment of SRC-1 for other Stat3 target genes and cell types, we hence asked whether binding of SRC-1 to Stat 3 regulatory elements might vary in a cell type- and/or gene-specific manner. To clarify this, we extended our study to HepG2 hepatocellular carcinoma cells. Analyzing the Stat 3 enhancer element of the gene encoding the acute-phase protein haptoglobin in HepG2 cells produced a similar pattern. Again, Stat3 was inducibly recruited to the promoter after IL-6 stimulation, while SRC-1 binding decreased (Fig. 2, lower panel). The same response was observed for the Stat3 sites upstream the c-fos and junB genes. To demonstrate that under the conditions applied, transcriptional induction of IL-6 target genes effectively ocurred, we investigated the presence of RNA polymerase II to the haptoglobin promoter. In fact, IL-6 strongly induced binding of the polymerase, as expected (Fig. 2). Likewise, coactivator $\mathrm{p} / \mathrm{CAF}$ and the Mediator subunit TRAP220/Med1 were detected at the haptoglobin promoter, and slightly enhanced binding was observed upon treatment with IL-6. Inducible binding was also found for the coactivators p300 and CBP (see below). We conclude that for the target genes studied in INA-6 and HepG2 cells, the transcriptional induction by IL-6 
involves Stat3 recruitment but reciprocally correlates with binding of SRC-1 to the promoter regions.

\section{SRC-1 silencing does not interfere with Stat 3 transactivating activity in HepG2 cells}

Our finding seemed to challenge the view that SRC-1 is generally required coactivator for Stat3. We therefore set out to investigate the role of the coactivator for the IL-6-induced expression of Stat 3 target genes in more detail. For that purpose, we silenced SRC-1 expression by transiently transfecting the above-mentioned shRNA vector into HepG2 cells and determined the promoter activity of the $\alpha_{1}$-antichymotrypsin (ACT) gene by a luciferase reporter assay. This promoter harbours two Stat3 binding sites that are essential for its induction by IL-6 [24]. As shown in Fig. $3 \mathrm{~A}, \mathrm{ACT}$ promoter activity did not change significantly when the cells were depleted of endogenous SRC-1. In contrast, silencing of Stat 3 expression using a shRNA vector described previously [31] resulted in an almost complete inhibition of reporter activation, as expected.

In additon to gene silencing approach, we obstructed Stat3 capability to interact with SRC-1. Within Stat3, the interaction site with SRC-1 has been localized to a carboxy-terminal region of the Stat 3 transactivation domain, and replacing leucine 755 and phenylalanine 757 by alanines (Stat3-LFAA) was demonstrated to generate a Stat3 mutant unable to recruit SRC-1 [20]. We constructed an expression vector coding for this Stat3-LFAA mutant. Furthermore, by introducing silent mutations into the shRNA target region within the Stat $3 \mathrm{cDNA}$, the expressed Stat3 mRNA was rendered resistant to this shRNA. Either Stat3-LFAA or wild-type Stat3 were then coexpressed with the sh-Stat3 vector, thereby knocking down endogenous Stat 3 and replacing it by exogenous either mutated or wild-type Stat3. Stat3 protein expression and phosphorylation was confirmed by immunoblottting (Fig. 3B). Reporter studies demonstrated that the Stat3-LFAA mutant activated the ACT promoter as efficiently as wild-type Stat3. The same proved to be true for the haptoglobin promoter (not shown). We conclude that at least in reporter gene assays, transactivation through Stat 3 of the genes studied does not require SRC- 1 .

Various nuclear receptors and other transcription factors are able to interact with all three members of the p160 family. We therefore asked whether SRC-2 and SRC-3 could take over the role from SRC-1 in our above studies and thereby conceal a functional requirement of SRC-1. To clarify this, vectors coding for shRNAs silencing SRC-2 and SRC-3 were constructed as described by Grenier et al. [32]. Successful reduction of protein levels was proven by immunoblot analysis in HEK-293 cells transfected with these vectors (Fig.4B). Silencing of SRC-2 or SRC-3 did not decrease ACT promoter activity (Fig. 4A). Even the combined silencing of all three p160 members did not interfere with Stat3 activity. As with SRC-1, ChIP experiments showed the presence of SRC-2 and SRC-3 at the Stat3 target promoters of the haptoglobin and junB genes (Fig. 4C). In contrast to SRC-1, however, SRC-2 binding tended to increase after IL-6 stimulation for both genes. The strong, constitutive presence of SRC-3 at the haptoglobin promoter was also further increased in response to IL-6. Hence, all three p160 family members are represented at Stat 3 target genes, and Stat 3 activation and binding to these regions might influence their ratio. In any case, however, our results demonstrate that neither of the p160 members seems to be essential for the Stat3-dependent transactivation of the Stat3 target promoters tested.

\section{In contrast to SRC-1, CBP is required for STAT3 transcriptional activation}

Coactivators of the $\mathrm{p} 300 / \mathrm{CBP}$ family were previously documented to interact with various STAT proteins including Stat3 $[8,33]$. It has been proposed that SRC-1 is essential for the recruitment of p300 and/or CBP to Stat3 target genes [7]. Since for the genes studied here, we were unable to 
detect an inducible recruitment of SRC-1, the question arose whether p300 and CBP can be recruited to such genes. As shown in Fig. 5A, binding of both coactivators to the Stat3responsive regions of the haptoglobin, junB, and c-fos promoters was strongly induced by IL-6. Overexpressing of CBP domains (fused to the Gal4 DNA-binding domain) that are known to contain STAT interaction sites turned out to be strongly inhibitory for a Stat3-driven reporter (Fig. 5B), whereas the cotransfected $\beta$-galactosidase vector, driven by the SV40 early promoter, was not affected (not shown). Expression of the fusion proteins was confirmed by immunoblotting (Fig. 5C). Similarly, when HEK-293 cells were used to monitor an endogenous Stat3 target gene, SOCS3, we observed a dramatic decrease in SOCS3 mRNA induction after transfecting the cells with the amino-terminal domain of CBP (Fig. 5D). In contrast, SRC-1 silencing by shRNA did not affect endogenous SOCS3 induction in this system. Therefore, in contrast to SRC-1, the activity of CBP and/or p300 is strictly required for the induction of the Stat 3 target genes investigated.

\section{Stable SRC-1 silencing does not block the induction of endogenous IL-6 target genes in HepG2 cells}

Although reporter gene assays are widely used to analyze gene regulation, they represent artificial scenarios whose regulatory attributes only partially resemble the situation at endogenous promoters. Therefore, we undertook to investigate a potential role of SRC-1 for the regulation of endogenous IL-6 target genes in HepG2 cells. For this purpose, HepG2 cells were infected with a lentiviral vector containing the SRC-1-directed shRNA expression cassette as well as the EGFP and neo genes for control of infection efficiency and selection, respectively. By selection with neomycin, HepG2 cells with permanently down-regulated SRC-1 expression (HepG2- $\triangle$ SRC1) were derived. Immunoblotting analysis verified the efficient knock-down of SRC-1 in these cells, as shown in Fig. 6A. Reporter gene assays performed with HepG2- $\Delta$ SRC1 as well as with unmanipulated HepG2 cells showed that IL-6-stimulated haptoglobin promoter activity was not reduced by SRC-1 silencing (Fig. 6B). The same proved to be true in case of the ACT promoter (not shown). Moreover, when HepG2- $\triangle \mathrm{SRC1}$ cells were studied by ChIP, inducible p300 and CBP binding to the haptoglobin promoter was observed in spite of the absence of SRC-1 (Fig. 6C). Therefore, SRC-1 is not essential for the recruitment of these coactivators to Stat 3 target genes.

To extend these studies to endogenous genes as discussed above, we isolated RNA from HepG2 and HepG2- $\triangle$ SRC1 cells that were either treated with IL-6 for 1 or $4 \mathrm{~h}$ or left untreated, and subjected it to a microarray analysis using Affymetrix HG-U133A GeneChips ${ }^{\circledR}$. Upon analysis of genes that were differentially expressed between unmanipulated and silenced HepG2 cells, only 11 genes were found to significantly differ in their expression levels by at least 2 fold (supplementary Table I). Remarkably, the most strongly down-regulated gene turned out to be the SRC-1 gene itself verifying its successful silencing. The microarray data were then analyzed for potential changes with respect to the regulation of IL-6 target genes. In control HepG2 cells, 93 and 139 genes were found to be significantly induced by at least 1.5 fold, and 103 and 87 down-regulated by 1 - and 4-h IL-6 treatments, respectively. Among the genes induced by IL-6 many already known IL-6 target genes were found. As shown in Fig. 6D, a comparison of data obtained for HepG2 and HepG2- $\triangle \mathrm{SRC} 1$ cells revealed no major differences with respect to their response to IL-6. For a selected number of genes, the microarray data were verified by real-time PCR with qualitatively identical results (not shown). Closer inspection of the data obtained for those genes with an established regulatory role of Stat3, e.g. the genes coding for suppressor of cytokine signaling 3 (SOCS3), junB, c-fos, growth and DNA damage-inducible 45- $\beta$ 
(GADD45 $\beta$ ), CCAAT/enhancer binding protein- $\delta$ (C/EBP $\delta$ ), interferon response factor-1 (IRF1 ), and the acute-phase protein haptoglobin clearly demonstrated that their responsiveness to IL-6 was not reduced by SRC-1 silencing (supplementary Figure). These findings indicated that SRC-1 is not required for the induction of endogenous IL-6 target genes in HepG2 cells.

Taken together, we conclude that recruitment of CBP/p300 to IL-6 target genes is initiated by the binding of activated Stat 3 to its enhancer elements and is essential for the transcriptional initiation of these genes. By contrast, SRC-1 - at least for the majority of Stat 3 target genes - is neither essential for $\mathrm{CBP} / \mathrm{p} 300$ recruitment nor for Stat3-driven transactivation. 


\section{DISCUSSION}

Previous reports have shown that particular p160 family members play an important role in the transcriptional activation by multiple transcription factors [34-36] including several members of the STAT family $[7,15,16,37,38]$. In several studies dealing with STAT-coactivator interactions, a significant role was assigned to SRC-1 but not to the other two p160 family members [7, 15, 16, 19, 39]. Reports indicating an involvement of SRC-1 in Stat 3 transcriptional activation were focused on the regulation of particular Stat 3 target genes, i.e. $p 21^{\text {waf }}$, junB, c-myc and cyclin D1[7, 19-21]. Yin et al. and Saxena et al. demonstrated that silencing of SRC-1 decreases leptin-stimulated and Stat3-dependent proliferation of MCF-7 mammary carcinoma cells $[19,21]$. In our study, we therefore addressed the question whether SRC-1 is also an essential coactivator for Stat3-mediated physiological effects of IL-6. We and others demonstrated previously that the IL-6-dependent survival and growth of multiple myeloma cells depends on Stat3 [25, 40]. Our current finding that silencing of SRC-1 induced a strong apoptotic response in INA-6 myeloma cells, and that this response was similar in extent and time course to the one provoked by Stat 3 silencing, seemed in line with the assumption of an essential role of SRC-1 for Stat3 function. Targeted disruption of the Stat 3 gene in mice is known to be lethal [22]. Recently, evidence was provided that CR6-interacting factor 1 (Crif1) is an essential transcriptional coactivator of Stat3. In fact, murine Crif1 (-/-) embryos die around E6.5 as a result of defective proliferation and massive apoptosis together with markedly reduced expression of Stat3 target genes in a Crif1 (-/-) blastocyst culture [10]. In contrast, SRC-1 (-/-) mice display a phenotype correlated to thyroid hormone resistance [23] but are viable and do not seem to indicate defects in Stat3-related functions

This apparent contradiction led us to investigate the involvement of SRC-1 in Stat3 action in more detail. Surprisingly, our ChIP analyses revealed that SRC-1 constitutively binds to Stat3dependent regulatory elements of the junB and BCL3 genes in INA-6 cells, with a decreased binding after IL-6 addition. Likewise, when several IL-6 target genes were tested by ChIP in HepG2 cells, the cytokine again decreased a constitutive SRC-1 binding to Stat3-responsive regions. These results are in contrast to previous reports from other laboratories [7, 19, 20]. Therefore, we repeated the experiments extensively employing different antibody sources and using the same experimental conditions as published but always obtained the same results. Hence, we do not know the reason for this discrepancy. The possibility exists that the Stat 3 sites of the myc, cyclin D1 and p2 $1^{\text {waf }}$ genes might behave differently [21]. In fact, we observed one Stat3 enhancer element, i.e. the 3' enhancer of the junB gene [41], that exhibited induced SRC-1 binding (data not shown). In case of the junB promoter, however, the ChIP primer sequences we used were identical to those published [20]. We do not have a plausible explanation for the conflicting results.

Numerous studies rely on overexpression of coactivators as an approach to examine their effects on the activity of transcription factors. For the promoters studied here, an enhancement of IL-6-dependent transcriptional activation by coexpression of SRC-1 in reporter gene assays might support its coactivator function. However, in our hands, this was observed only when SRC-1 levels were raised to high, probably nonphysiological levels and when the resulting luciferase data were normalized to protein concentration (data not shown). We therefore reasoned that down-regulating SRC-1 function might provide a more reliable insight into the role of this coactivator for Stat 3 transcriptional activation.

Furthermore, our data using an shRNA targeting SRC-1 expression clearly show that the Stat 3 target promoters investigated do not rely on SRC-1 function. In contrast, we repeatedly observed a slight stimulatory effect on promoter activities in reporter gene assays after SRC-1 
functional knock-down. To extend this study to a more global survey of IL-6 target genes, we generated HepG2 cells with permanently silenced SRC-1 expression. Upon microarray analysis of these HepG2- $\triangle \mathrm{SRC} 1$ as well as control HepG2 cells, covering more than 20,000 genes, we observed an overall comparable pattern of IL-6-induced expression changes. Therefore, our notion that SRC-1 is dispensible for IL-6-induced transcription as concluded from reporter assays for a limited number of genes, also applies when IL-6 target genes are studied genomewide. We conclude further that the induction of apoptosis in myeloma cells upon SRC-1 silencing is most likely not due to an intereference with Stat 3 funcion but rather indicates that SRC-1 is essential for another process in these cells. Likewise, the reduction of mammary carcinoma cell growth after knock-down of SRC-1 as observed by Yin et al. [19,21] might be due to functional interference with growth-controlling transcription factors other than Stat3.

There is considerable evidence for a compensatory balance between the three p160 family members $[42,43]$. We therefore included SRC-2 and SRC-3 in our study. In fact, both p160 members were able to bind to Stat 3 elements in various IL-6 target genes. For most elements studied, SRC-2 and SRC-3 binding was constitutive but increased slightly after IL-6 stimulation. A number of studies have revealed that many transcription factors can interact with any of the three p160 proteins [34, 44, 45]. Recruitment of p160 factors does not necessarily occur synchronously. Gao et al. showed that each p160 protein has a stage-specific function in the

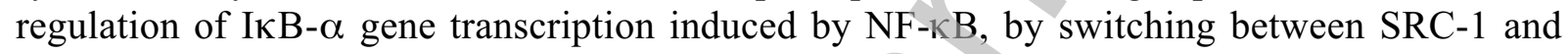
SRC-2 on IKB- $\alpha$ gene promoter in the course of gene transcription [46]. The data presented here might also suggest such a differential recruitment of individual p160 coactivators to regulatory elements of IL-6 target genes. However, neither individually knocking down p160 family members by shSRC expression vectors nor in combination reduced transcriptional activation by Stat 3 as observed in reporter gene assays. Collectively, these data demonstrate that neither of the p160 members seems to be essential for the Stat3-dependent transactivation.

Previous reports have indicated an involvement of CBP and/or p300 in Stat3 transcriptional activation $[7,8,47,48]$. In the present study, and in contrast to the results obtained for SRC-1, we observed an IL-6-inducible recruitment of both p300 and CBP to Stat 3 target elements. Furthermore, by overexpressing dominant-negative CBP fusion proteins we demonstrated a functional importance of these coactivators for the transactivating potential of Stat3. Our results provide evidence that neither the ability of CBP and p300 to enhance Stat3-dependent gene expression nor their recruitment to Stat 3 sites are dependent on SRC-1. 


\section{ACKNOWLEGDEMENTS}

We thank Stefan Rose-John (University of Kiel, Germany) for recombinant IL-6, Martin Gramatzki (University of Kiel, Germany) for cell line INA-6, and the core unit "DNA technology" (Interdisciplinary Center for Clinical Research Leipzig, Knut Krohn) for microarray studies. This work was supported by the Interdisciplinary Center for Clinical Research (IZKF, project A13) at the University of Leipzig and by SFB610 (project C2) from the Deutsche Forschungsgemeinschaft. 


\section{REFERENCES}

1 Wegenka, U. M., Buschmann, J., Lütticken, C., Heinrich, P. C. and Horn, F. (1993) Acute-phase response factor, a nuclear factor binding to acute-phase response elements, is rapidly activated by interleukin-6 at the posttranslational level. Mol. Cell. Biol. 13, 276-88.

2 Lütticken, C., Wegenka, U. M., Yuan, J., Buschmann, J., Schindler, C., Ziemiecki, A., Harpur, A. G., Wilks, A. F., Yasukawa, K., Taga, T., Kishimoto, T., Barbieri, G., Pellegrini, S., Sendtner, M., Heinrich, P. C. and Horn, F. (1994) Association of transcription factor APRF and protein kinase JAK1 with the IL-6 signal transducer gp130. Science 263, 89-92

3 Yuan, J., Wegenka, U. M., Lütticken, C., Buschmann, J., Decker, T., Schindler, C., Heinrich, P. C. and Horn, F. (1994) The signalling pathways of interleukin-6 and gamma interferon converge by the activation of different transcription factors which bind to common responsive DNA elements. Mol. Cell. Biol. 14, 1657-68.

4 Bromberg, J. F., Horvath, C. M., Besser, D., Lathem, W. W. and Darnell, J. E., Jr. (1998) Stat3 activation is required for cellular transformation by v-src. Mol. Cell. Biol. 18, 2553-8

5 Bromberg, J. F., Wrzeszczynska, M. H., Devgan, G., Zhao, Y., Pestell, R. G., Albanese, C. and Darnell, J. E., Jr. (1999) Stat3 as an oncogene. Cell 98, 295-303

6 Kortylewski, M., Jove, R. and Yu, H. (2005) Targeting STAT3 affects melanoma on multiple fronts. Cancer Metastasis Rev. 24, 315-27

7 Giraud, S., Bienvenu, F., Avril, S., Gascan, H., Heery, D. M. and Coqueret, O. (2002) Functional interaction of STAT3 transcription factor with the coactivator NcoA/SRC1a. J. Biol. Chem. 277, 8004-11

8 Paulson, M., Pisharody, S., Pan, L., Guadagno, S., Mui, A. L. and Levy, D. E. (1999) Stat protein transactivation domains recruit $\mathrm{p} 300 / \mathrm{CBP}$ through widely divergent sequences. J. Biol. Chem. 274, 25343-9

9 Lufei, C., Koh, T. H., Uchida, T. and Cao, X. (2007) Pin1 is required for the Ser727 phosphorylation-dependent Stat3 activity. Oncogene 26, 7656-64

10 Kwon, M. C., Koo, B. K., Moon, J. S., Kim, Y. Y., Park, K. C., Kim, N. S., Kwon, M. Y., Kong, M. P., Yoon, K. J., Im, S. K., Ghim, J., Han, Y. M., Jang, S. K., Shong, M. and Kong, Y. Y. (2008) Crif1 is a novel transcriptional coactivator of STAT3. EMBO J. 27, 642-53

11 Ogryzko, V. V., Schiltz, R. L., Russanova, V., Howard, B. H. and Nakatani, Y. (1996) The transcriptional coactivators $\mathrm{p} 300$ and CBP are histone acetyltransferases. Cell 87, 953-9 Bannister, A. J. and Kouzarides, T. (1996) The CBP co-activator is a histone acetyltransferase. Nature 384, 641-3

Zhang, J. J., Vinkemeier, U., Gu, W., Chakravarti, D., Horvath, C. M. and Darnell, J. E., Jr. (1996) Two contact regions between Stat1 and CBP/p300 in interferon gamma signaling. Proc. Natl. Acad. Sci. USA 93, 15092-6

14 Lee, J. W., Lee, Y. C., Na, S. Y., Jung, D. J. and Lee, S. K. (2001) Transcriptional coregulators of the nuclear receptor superfamily: coactivators and corepressors. Cell. Mol. Life Sci. 58, 289-97 Litterst, C. M. and Pfitzner, E. (2001) Transcriptional activation by STAT6 requires the direct interaction with NCoA-1. J. Biol. Chem. 276, 45713-21 Litterst, C. M., Kliem, S., Marilley, D. and Pfitzner, E. (2003) NCoA-1/SRC-1 is an essential coactivator of STAT5 that binds to the FDL motif in the alpha-helical region of the STAT5 transactivation domain. J. Biol. Chem. 278, 45340-51

Razeto, A., Ramakrishnan, V., Litterst, C. M., Giller, K., Griesinger, C., Carlomagno, T., Lakomek, N., Heimburg, T., Lodrini, M., Pfitzner, E. and Becker, S. (2004) Structure of the NCoA-1/SRC-1 PAS-B domain bound to the LXXLL motif of the STAT6 transactivation domain. J. Mol. Biol. 336, 319-29

Lodrini, M., Munz, T., Coudevylle, N., Griesinger, C., Becker, S. and Pfitzner, E. (2008) $\mathrm{P} 160 / \mathrm{SRC} / \mathrm{NCoA}$ coactivators form complexes via specific interaction of their PAS-B domain with the CID/AD1 domain. Nucleic Acids Res. 36, 1847-60

19 Yin, N., Wang, D., Zhang, H., Yi, X., Sun, X., Shi, B., Wu, H., Wu, G., Wang, X. and Shang, Y. 
(2004) Molecular mechanisms involved in the growth stimulation of breast cancer cells by leptin. Cancer Res. 64, 5870-5

20 Zhao, H., Nakajima, R., Kunimoto, H., Sasaki, T., Kojima, H. and Nakajima, K. (2004) Region 752-761 of STAT3 is critical for SRC-1 recruitment and Ser727 phosphorylation. Biochem. Biophys. Res. Commun. 325, 541-8

21 Saxena, N. K., Vertino, P. M., Anania, F. A. and Sharma, D. (2007) leptin-induced growth stimulation of breast cancer cells involves recruitment of histone acetyltransferases and mediator complex to CYCLIN D1 promoter via activation of Stat3. J. Biol. Chem. 282, 13316-25 Takeda, K., Noguchi, K., Shi, W., Tanaka, T., Matsumoto, M., Yoshida, N., Kishimoto, T. and Akira, S. (1997) Targeted disruption of the mouse Stat3 gene leads to early embryonic lethality. Proc. Natl. Acad. Sci. USA 94, 3801-4

23 Weiss, R. E., Xu, J., Ning, G., Pohlenz, J., O'Malley, B. W. and Refetoff, S. (1999) Mice deficient in the steroid receptor co-activator 1 (SRC-1) are resistant to thyroid hormone. EMBO J. 18, 1900-4

24 Kordula, T., Rydel, R. E., Brigham, E. F., Horn, F., Heinrich, P. C. and Travis, J. (1998) Oncostatin $M$ and the interleukin-6 and soluble interleukin-6 receptor complex regulate alpha1antichymotrypsin expression in human cortical astrocytes. J. Biol. Chem. 273, 4112-8. Brocke-Heidrich, K., Kretzschmar, A. K., Pfeifer, G., Henze, C., Löffler, D., Koczan, D., Thiesen, H. J., Burger, R., Gramatzki, M. and Horn, F. (2004) Interleukin-6-dependent gene expression profiles in multiple myeloma INA-6 cells reveal a Bcl-2 family-independent survival pathway closely associated with Stat3 activation. Blood 103, 242-51

26 Brummelkamp, T. R., Bernards, R. and Agami, R. (2002) A System for Stable Expression of Short Interfering RNAs in Mammalian Cells. Science 296, 550-3.

27 Zhang, H., Yi, X., Sun, X., Yin, N., Shi, B., Wu, H., Wang, D., Wu, G. and Shang, Y. (2004) Differential gene regulation by the SRC family of coactivators. Genes Dev. 18, 1753-65 Bellido, T., O'Brien, C. A., Roberson, P. K. and Manolagas, S. C. (1998) Transcriptional activation of the p21(WAF1,CIP1,SDI1) gene by interleukin-6 type cytokines. A prerequisite for their pro- differentiating and anti-apoptotic effects on human osteoblastic cells. J. Biol. Chem. 273, 21137-44.

29 Andrews, N. C. and Faller, D. V. (1991) A rapid micropreparation technique for extraction of DNA-binding proteins from a limited number of mammalian cells. Nucleic Acids Res. 19, 2499 Burger, R., Guenther, A., Bakker, F., Schmalzing, M., Bernand, S., Baum, W., Duerr, B., Hocke, G. M., Steininger, H., Gebhart, E. and Gramatzki, M. (2001) Gp130 and ras mediated signaling in human plasma cell line INA-6: a cytokine-regulated tumor model for plasmacytoma. Hematol. J. 2, 42-53.

31 Brocke-Heidrich, K., Ge, B., Cvijic, H., Pfeifer, G., Löffler, D., Henze, C., McKeithan, T. W. and Horn, F. (2006) BCL 3 is induced by IL-6 via Stat3 binding to intronic enhancer HS4 and represses its own transcription. Oncogene 25, 7297-304 Mantel, A., Schumacher, M. and Massaad, C. (2004) Selective recruitment of p160 coactivators on glucocorticoid-regulated promoters in Schwann cells. Mol. Endocrinol. 18, 2866-79 Nakashima, K., Yanagisawa, M., Arakawa, H., Kimura, N., Hisatsune, T., Kawabata, M., Miyazono, K. and Taga, T. (1999) Synergistic signaling in fetal brain by STAT3-Smad1 complex bridged by $\mathrm{p} 300$. Science 284, 479-82

34 Beischlag, T. V., Wang, S., Rose, D. W., Torchia, J., Reisz-Porszasz, S., Muhammad, K., Nelson, W. E., Probst, M. R., Rosenfeld, M. G. and Hankinson, O. (2002) Recruitment of the NCoA/SRC-1/p160 family of transcriptional coactivators by the aryl hydrocarbon receptor/aryl hydrocarbon receptor nuclear translocator complex. Mol. Cell. Biol. 22, 4319-33

35 Na, S. Y., Lee, S. K., Han, S. J., Choi, H. S., Im, S. Y. and Lee, J. W. (1998) Steroid receptor coactivator-1 interacts with the p50 subunit and coactivates nuclear factor kappaB-mediated transactivations. J. Biol. Chem. 273, 10831-4 Onate, S. A., Tsai, S. Y., Tsai, M. J. and O'Malley, B. W. (1995) Sequence and characterization 
of a coactivator for the steroid hormone receptor superfamily. Science 270, 1354-7

Litterst, C. M. and Pfitzner, E. (2002) An LXXLL motif in the transactivation domain of STAT6 mediates recruitment of NCoA-1/SRC-1. J. Biol. Chem. 277, 36052-60

38 Torchia, J., Rose, D. W., Inostroza, J., Kamei, Y., Westin, S., Glass, C. K. and Rosenfeld, M. G. (1997) The transcriptional co-activator p/CIP binds CBP and mediates nuclear-receptor function. Nature 387, 677-84

39 Goenka, S., Marlar, C., Schindler, U. and Boothby, M. (2003) Differential roles of C-terminal activation motifs in the establishment of Stat6 transcriptional specificity. J. Biol. Chem. 278, 50362-70

40 Catlett-Falcone, R., Landowski, T. H., Oshiro, M. M., Turkson, J., Levitzki, A., Savino, R., Ciliberto, G., Moscinski, L., Fernandez-Luna, J. L., Nunez, G., Dalton, W. S. and Jove, R. (1999) Constitutive activation of Stat3 signaling confers resistance to apoptosis in human U266 myeloma cells. Immunity 10, 105-15.

41 Brown, R. T., Ades, I. Z. and Nordan, R. P. (1995) An acute phase response factor/NF-kappa B site downstream of the junB gene that mediates responsiveness to interleukin-6 in a murine plasmacytoma. J. Biol. Chem. 270, 31129-35

$42 \mathrm{Xu}, \mathrm{J}$. and Li, Q. (2003) Review of the in vivo functions of the p160 steroid receptor coactivator family. Mol. Endocrinol. 17, 1681-92

43 Weiss, R. E., Gehin, M., Xu, J., Sadow, P. M., O'Malley, B. W., Chambon, P. and Refetoff, S. (2002) Thyroid function in mice with compound heterozygous and homozygous disruptions of SRC-1 and TIF-2 coactivators: evidence for haploinsufficiency. Endocrinology 143, 1554-7 Webb, P., Nguyen, P., Shinsako, J., Anderson, C., Feng, W., Nguyen, M. P., Chen, D., Huang, S. M., Subramanian, S., McKinerney, E., Katzenellenbogen, B. S., Stallcup, M. R. and Kushner, P. J. (1998) Estrogen receptor activation function 1 works by binding p160 coactivator proteins. Mol. Endocrinol. 12, 1605-18

45 Goel, A. and Janknecht, R. (2004) Concerted activation of ETS protein ER81 by p160 coactivators, the acetyltransferase p300 and the receptor tyrosine kinase HER2/Neu. J. Biol. Chem. 279, 14909-16

46 Gao, Z., Chiao, P., Zhang, X., Lazar, M. A., Seto, E., Young, H. A. and Ye, J. (2005) Coactivators and corepressors of NF-kappaB in IkappaB alpha gene promoter. J. Biol. Chem. 280, 21091-8

47 Ray, S., Sherman, C. T., Lu, M. and Brasier, A. R. (2002) Angiotensinogen Gene Expression Is Dependent on Signal Transducer and Activator of Transcription 3-Mediated p300/cAMP Response Element Binding Protein-Binding Protein Coactivator Recruitment and Histone Acetyltransferase Activity. Mol. Endocrinol. 16, 824-36. transcriptional activation by association of $\mathrm{p} 300$ with STAT3 upon IL-6 stimulation. FEBS Lett. 495, 71-6 


\section{FIGURE LEGENDS}

Figure 1: SRC-1 silencing induces apoptosis in IL-6-dependent INA-6 human multiple myeloma cells as does silencing of Stat3

(A) Silencing efficiency of a small hairpin RNA targeted to the SRC-1 mRNA was verified by its expression from the vector pSUPER-shSRC-1, transfected transiently by the calcium phosphate coprecipitation method into HEK-293 cells. $48 \mathrm{~h}$ posttransfection, cells were harvested and equal aliquots of nuclear extracts or whole cell lysates subjected to SDS-PAGE and immunoblotting using antibodies to SRC-1 or to ERK as a loading control. $(\mathbf{B}, \mathbf{C})$ Multiple myeloma INA-6 cells were transiently transfected with pSUPER-shSRC-1, pSUPER-shStat3, or a vector encoding an shRNA with scrambled sequence (sh-scrambled). After the time periods indicated, apoptosis was measured by a flow-cytometric Annexin V assay. By gating to EGFP fluorescence, the analysis was restricted to successfully transfected cells. In $C$, viable cell counts obtained for the shscrambled control were set as $100 \%$. The figure shows the results of a representative experiment from 3 independent studies.

Figure 2: SRC-1 association with Stat3 target promoters is decreased rather than increased after IL-6 stimulation of INA-6 myeloma and HepG2 hepatocellular carcinoma cells

INA-6 and HepG2 cells were stimulated with $10 \mathrm{ng} / \mathrm{ml} \mathrm{IL-6} \mathrm{for} 30 \mathrm{~min}$, where indicated. ChIP was carried out with $5 \mu \mathrm{g}$ of the antibodies indicated, or with immunoglobulin as a control. PCR was done using primers that cover the regions of Stat3 binding sites in the BCL3 intronic enhancer HS4, the haptoglobin, c-fos and junB promoters as well as primers covering a region in the $\beta$-actin gene as a control. For further control, PCR was also carried out for total input chromatin (input).

Figure 3: Activation of acute-phase gene promoters through Stat3 does not require SRC-1 (A) HepG2 cells were transiently transfected with $0.1 \mu \mathrm{g}$ each of ACT luciferase and $\beta$ galactosidase reporters, and with $2.8 \mu \mathrm{g}$ of the pSUPER vectors encoding the shRNAs indicated or empty pSUPER. Two days after transfection, cells were stimulated with IL-6 $(10 \mathrm{ng} / \mathrm{ml})$ for 6 $\mathrm{h}$ or left unstimulated. Luciferase activities as measured in cell extracts were normalized to $\beta$ galactosidase. Mean and standard deviation of three transfections are shown. Evaluation by Student's T test demonstrated no signicant difference between values for sh-SRC-1 and IL-6treated control cells. (B) HepG2 cells were transfected with ACT luciferase and $\beta$-galactosidase vectors as above. Endogenous Stat3 was silenced by cotransfection of pSUPER-shStat3 $(1.9 \mu \mathrm{g})$, and $0.3 \mu \mathrm{g}$ vectors expressing either silencing-resistant wild-type Stat3 or the mutated form Stat3-L755A/F757A (LFAA). Mean and standard deviation of three independent transfections are shown. No significant difference was observed between wt and LFAA Stat3 values. Stat3 protein expression and phosphorylation was confirmed by immunoblotting. Antibody to $\beta$-actin served as a loading control.

Figure 4: Silencing of SRC family members does not interfere with Stat3 transcriptional activity

(A) HepG2 cells were transfected with ACT reporter and pSUPER vectors and stimulated by IL6 as above. Mean and standard deviation of three experiments are shown. Significance was calculated by Student's T test and p values $<0.1\left(^{*}\right), 0.01(* *)$, and $0.001(* * *)$ are indicated. (B) HEK293 cells were transiently transfected with pSUPER vectors encoding shRNAs $(7.75 \mu \mathrm{g})$ targeting SRC-2 (sh-SRC-2), SRC-3 (sh-SRC-3), or a scrambled shRNA negative control (sh- 
ctr). An expression vector for enhanced GFP $(0.25 \mu \mathrm{g})$ was cotransfected to monitor transfection efficiency. Cells were harvested $48 \mathrm{~h}$ after transfection, and cell lysates analyzed by immunoblotting. These results were reproduced in three independent experiments. Erk1 antibody served as a loading control. (C) The presence of SRC-2 and SRC-3 at Stat3 target regions of the haptoglobin and junB promoters was determined by ChIP analysis of HepG2 cells as described in Fig. 2.

Figure 5: CBP is required for activation of acute-phase gene promoters through Stat3

(A) IL-6-dependent recruitment of p300 and CBP to Stat3 target promoter regions was studied in HepG2 cells as described in Fig. 2. (B) HepG2 cells were transfected with ACT luciferase and $\beta$ galactosidase constructs as above. In addition, $0.3 \mu \mathrm{g}$ of expression vectors for the Gal4-CBP fusion proteins indicated or an equivalent amount of empty vector were cotransfected. After stimulation with IL-6 (10 ng/ml) for $6 \mathrm{~h}$, luciferase and $\beta$-galactosidase activities were determined. Mean and standard deviation of 3 transfections are shown. (C) Gal4-CBP fusion protein expression was confirmed by immunoblotting, using antibody to Gal4. (D) HEK-293 cells were transfected with $2 \mu \mathrm{g}$ and $5 \mu \mathrm{g}$ of Stat 3 and Eg expression vectors, respectively. Eg represents an erythropoietin/gp130 receptor chimera that elicits Stat3 signaling upon erythropoietin stimulation. Furthermore, expression vectors $(13 \mu \mathrm{g})$ for Gal4-CBP(1-451) and pSUPER-shSRC-1 were cotransfected as indicated. $48 \mathrm{~h}$ posttransfection, cells were stimulated with erythropoietin $(7 \mathrm{U} / \mathrm{ml})$ for $1 \mathrm{~h}$ or left unstimulated. SOCS3 mRNA levels were determined by quantitative real-time PCR and normalized to glyceraldehyde-3-phosphate dehydrogenase mRNA as an internal control. Mean and standard deviation of three independent transfections are shown. Significance (T test) p values $<0.01(* *)$, and $0.001(* * *)$ are indicated.

Figure 6: Stable SRC-1 knock-down by RNA interference in HEPG2 cells does not change IL-6 target gene expression patterns

To permanently silence SRC-1 expression in HepG2 cells, an sh-SRC-1 expression vector was introduced by lentiviral infection. Selection by G418 for successfully transduced cells yielded HepG2- $\triangle$ SRC1 cells. (A) Efficiency of SRC-1 silencing was verified by immunoblots of nuclear extracts or whole cell lysates of HepG2- $\Delta$ SRC1 cells or HepG2 cells mock-transduced with an empty vector. (B) Activities of the haptoglobin promoter in HepG2- $\Delta$ SRC1 or control HepG2 cells were determined by reporter gene assay as described above. Values derived from three independent experiments are shown as luciferase activity relative to IL-6-treated control HepG2 cells. (C) Binding of Stat 3 and coactivators of the p160 and p300 families to the haptoglobin promoter in HepG2- $\triangle$ SRC1 was analyzed by ChIP as described in Fig. 2. $\beta$-Actin and total input chromatin controls demonstrating specificity and equal loading were performed but were not included in the figure. (D) HepG2- $\triangle \mathrm{SRC} 1$ or control HepG2 cells were treated with $10 \mathrm{ng} / \mathrm{ml} \mathrm{IL}-$ 6 for 1 or $4 \mathrm{~h}$ or left untreated. Thereafter, total RNA was isolated and used for hybridization on Affymetrix GeneChips HG-U113A. Two independent experiment series were carried out. Genes expressed differentially in response to IL-6 as compared to the untreated controls are shown (left four columns), with the colors representing the fold-induction or -repression as indicated beneath. For the same genes, the right column compares the mean expression levels of HepG2$\triangle \mathrm{SRC} 1$ and control HepG2 cells. 
Figure 1

A

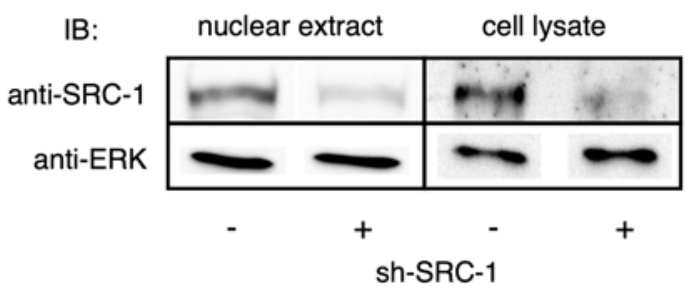

C
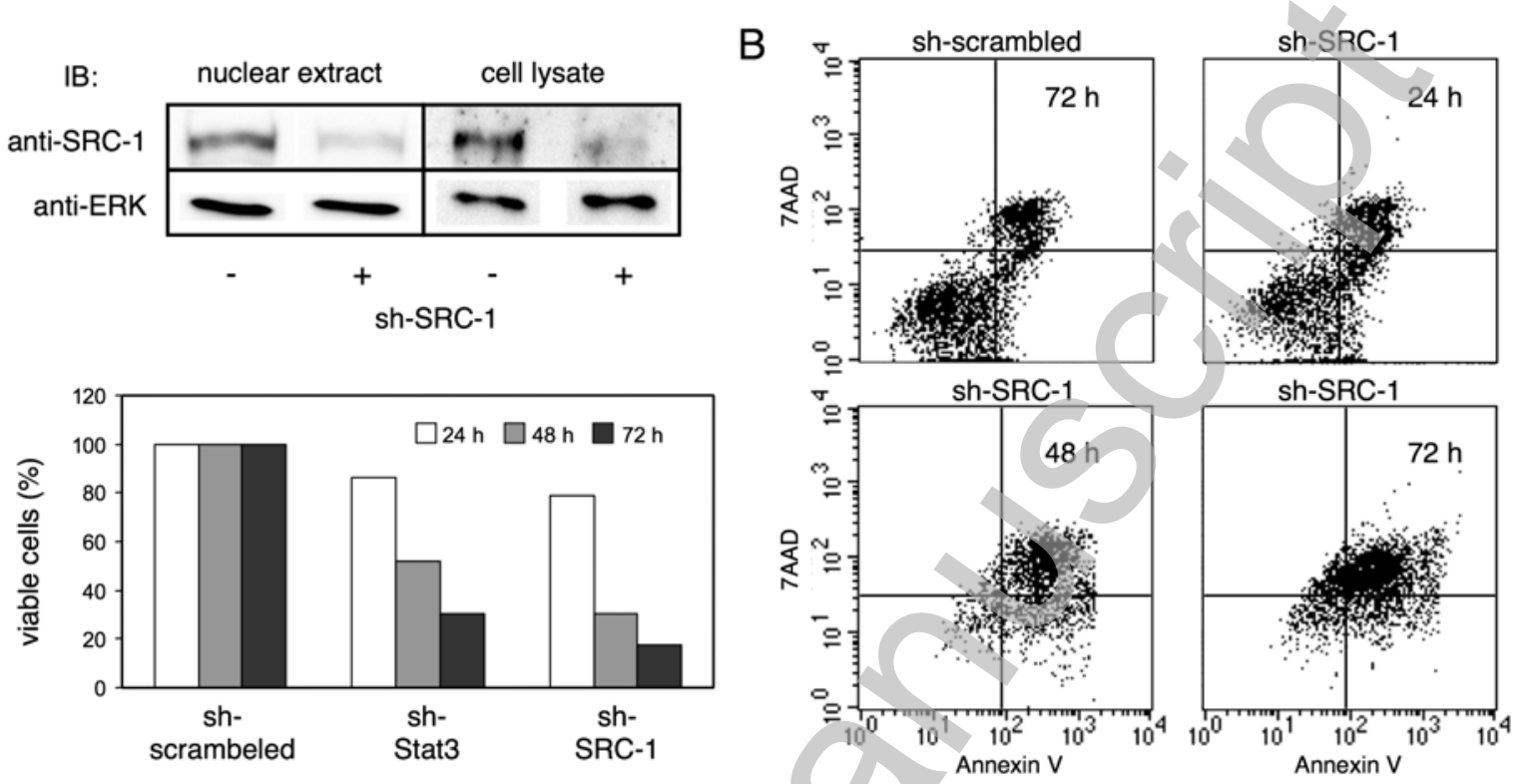
Figure 2

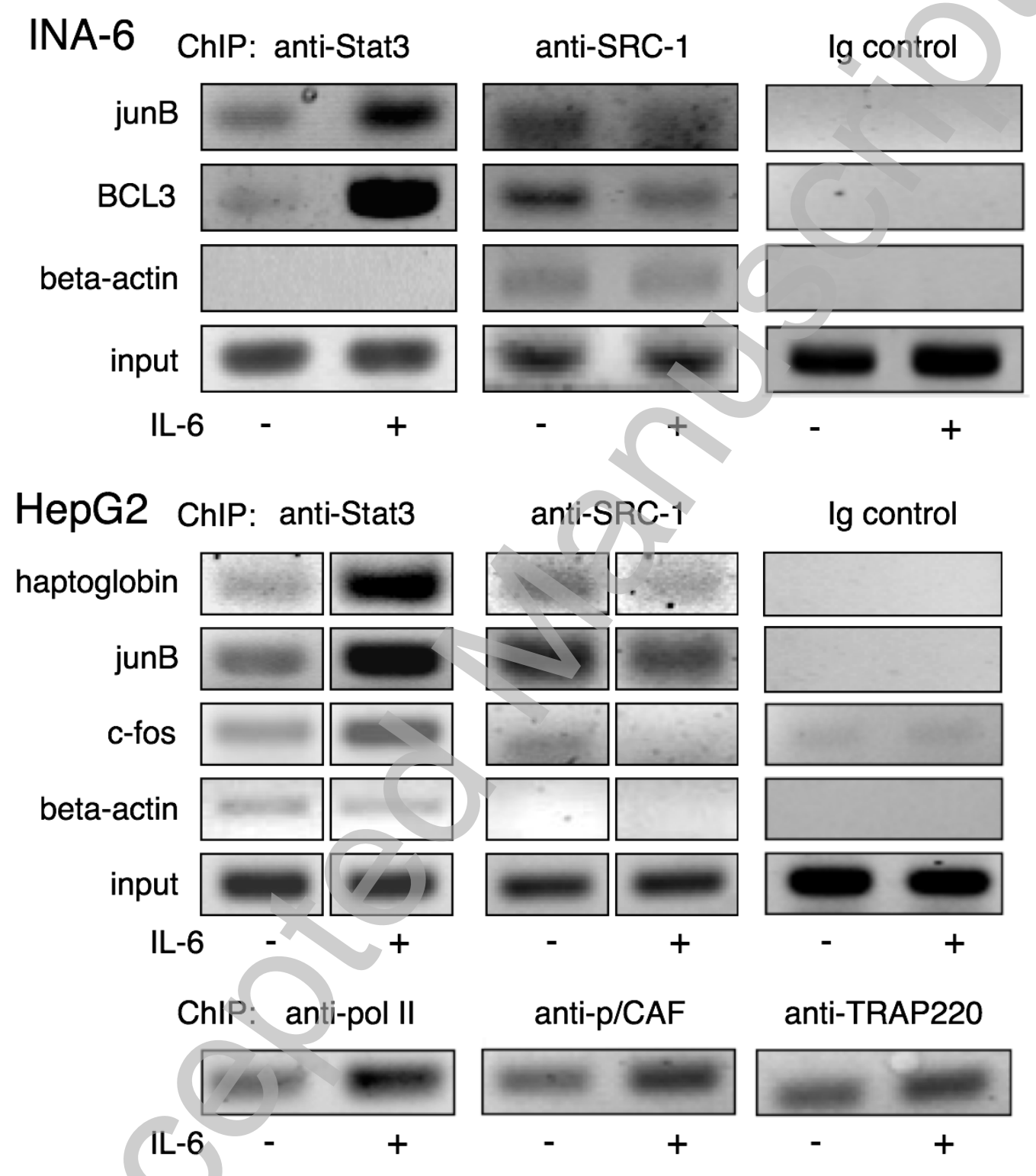


Figure 3

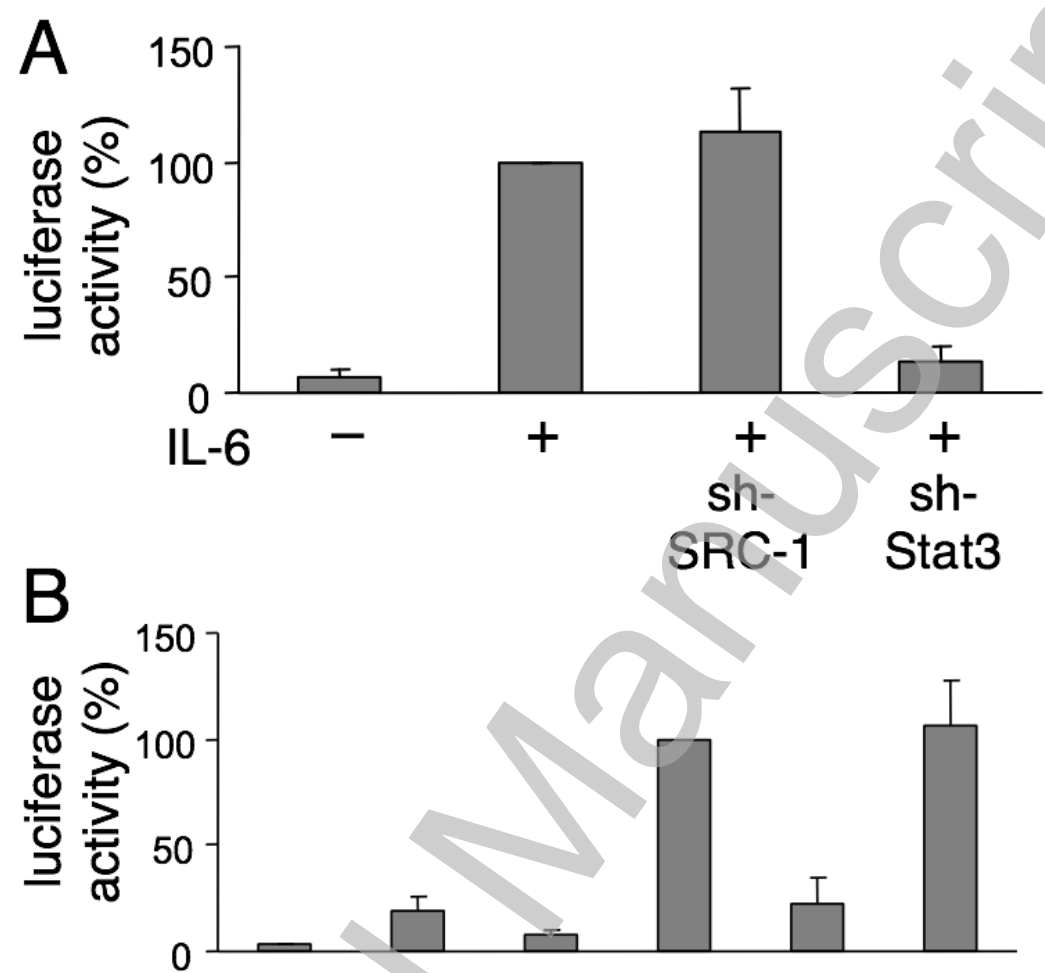

IB:
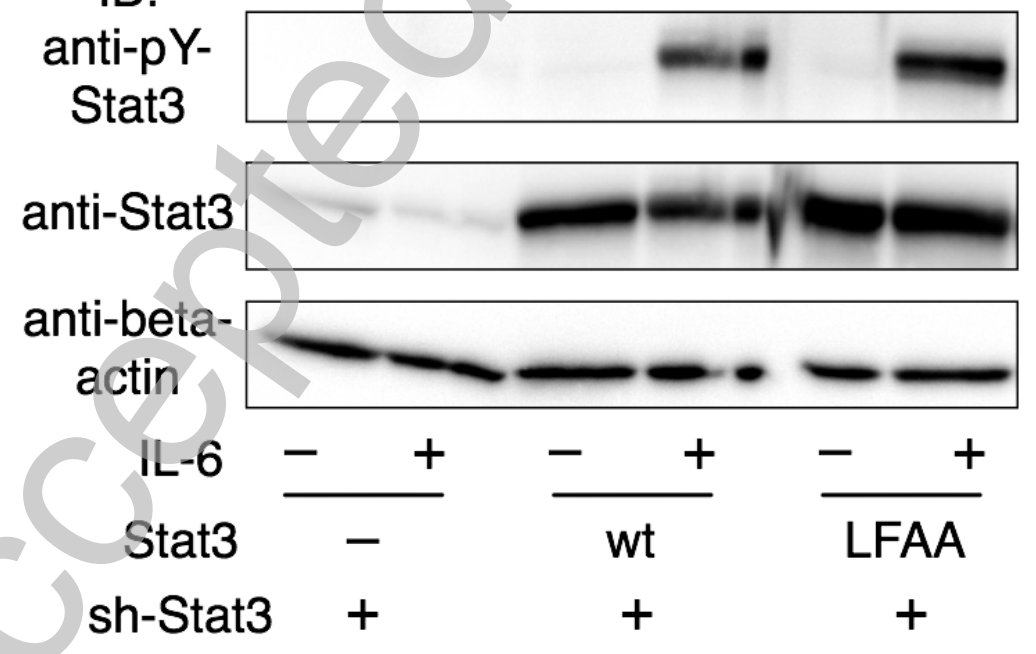
Figure 4

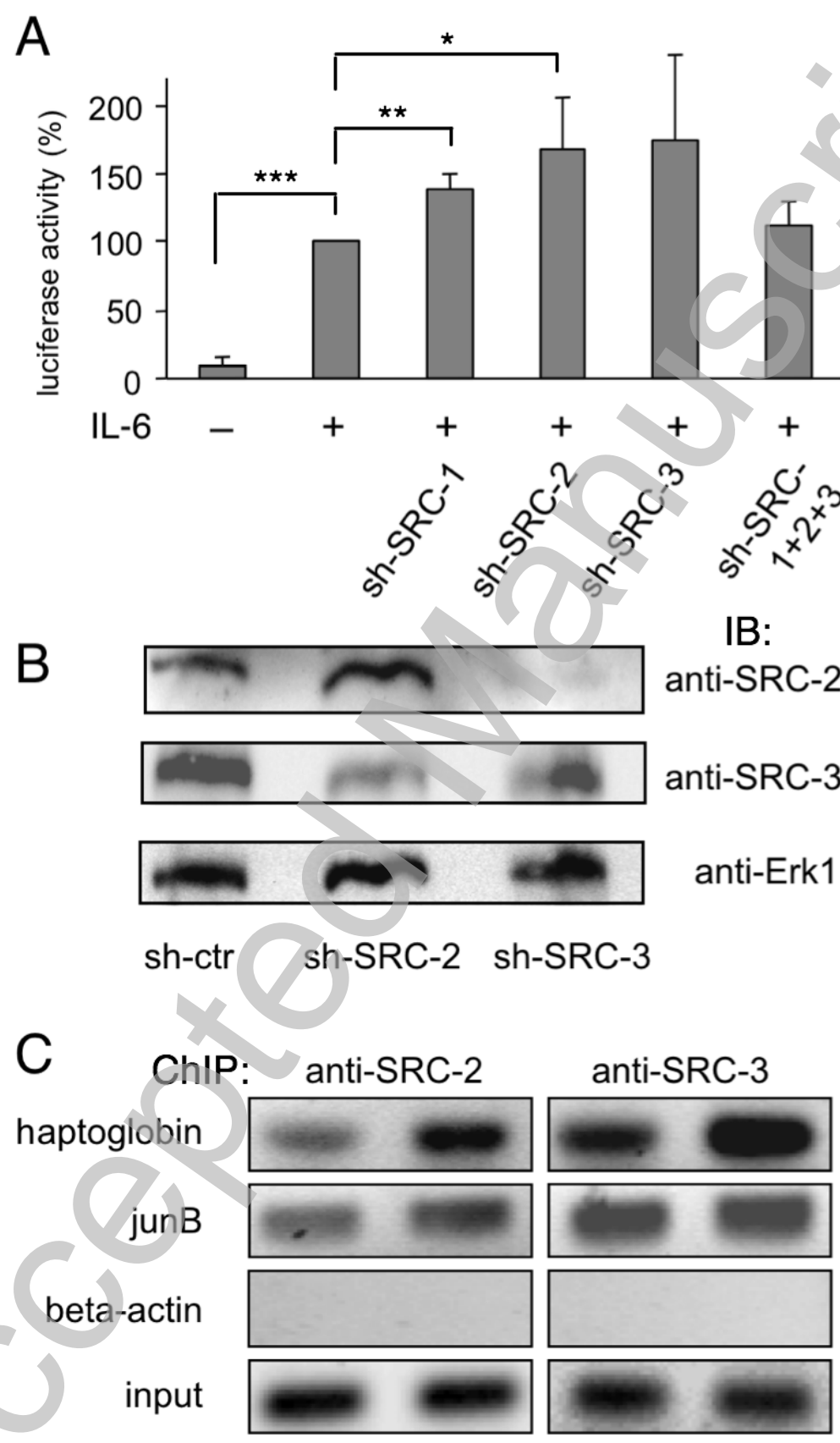


Figure 5

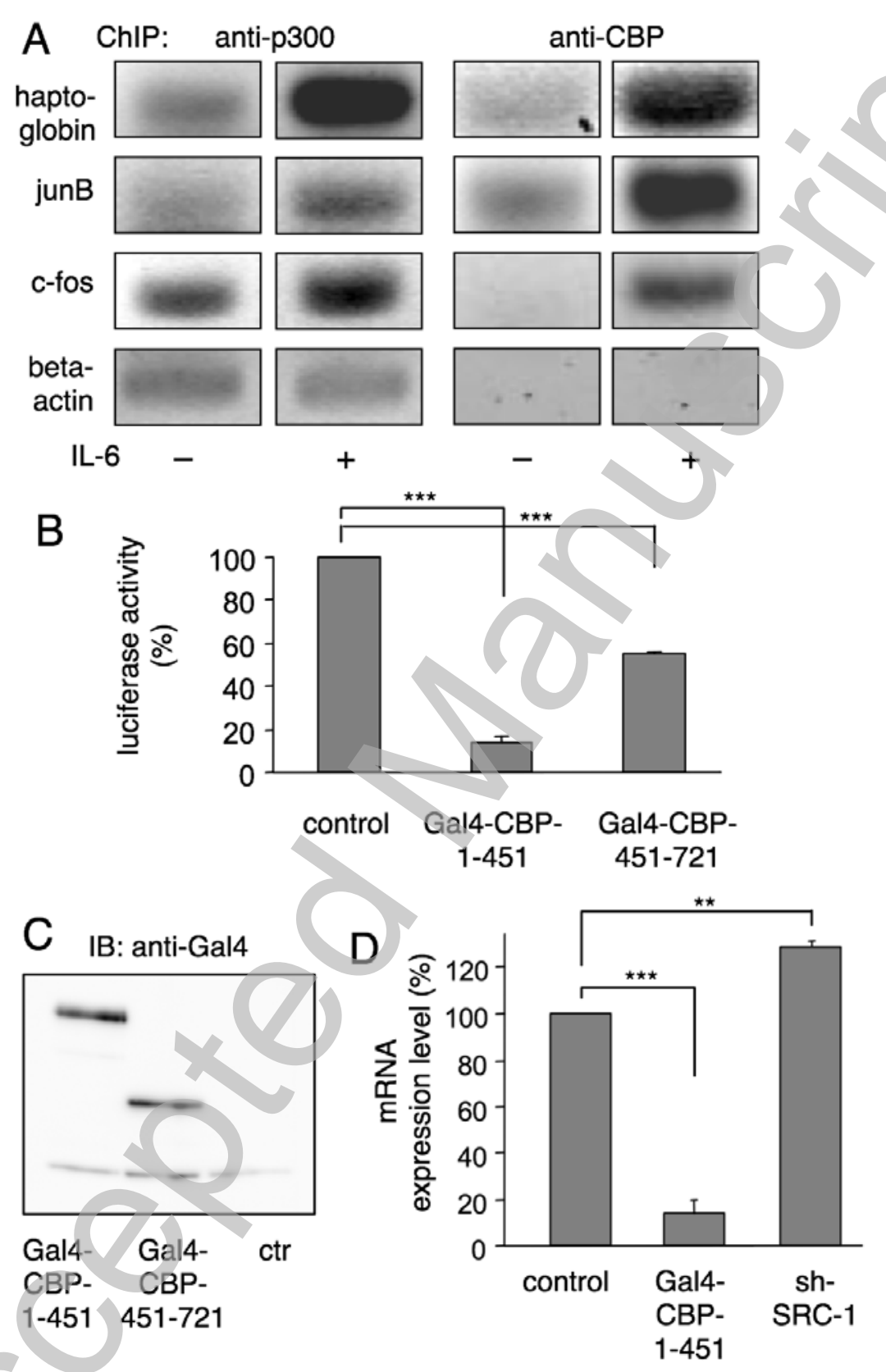


Figure 6

A

IB:

nuclear extract cell lysate

anti-SRC-1

anti-ERK

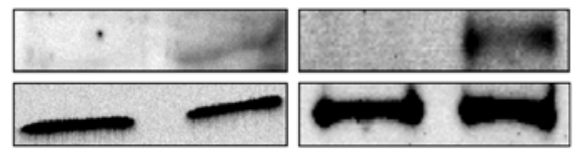

HepG2- HepG2 HepG2- HepG2 $\triangle S R C 1 \quad \Delta S R C 1$

B

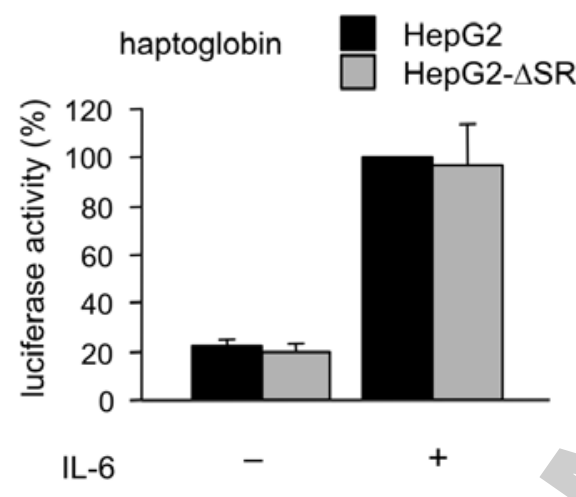

C

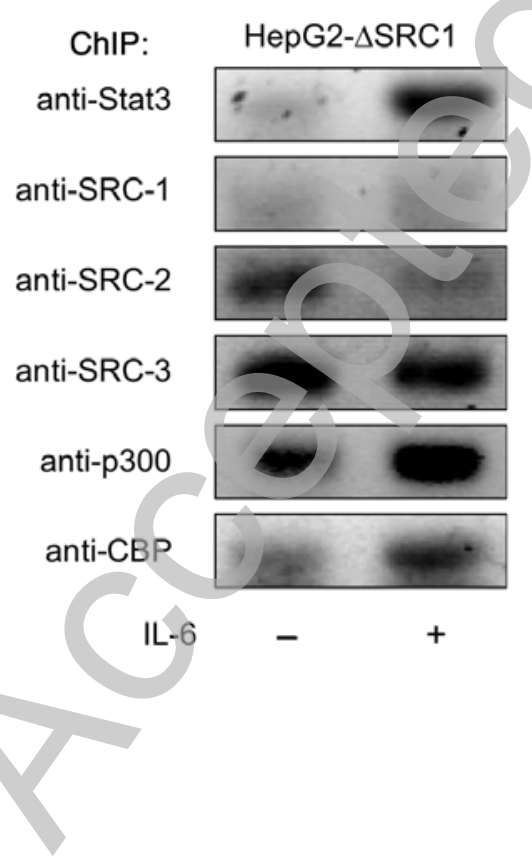

D
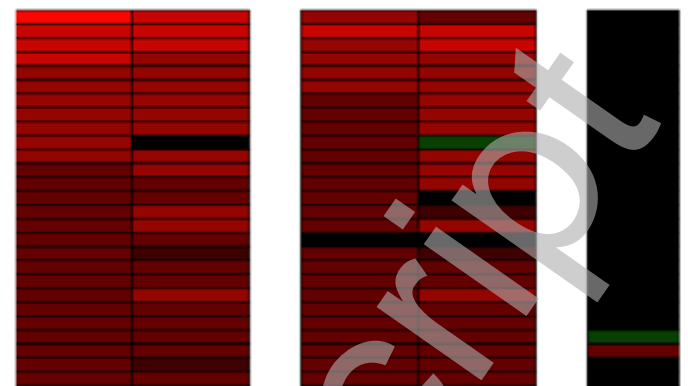
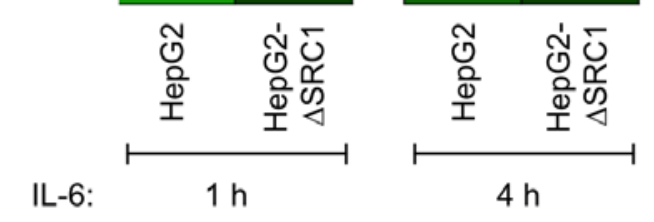

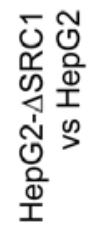

induced > $\begin{array}{lllllllllll}16 & 8 & 4 & 2 & 1.5 & 0 & 1.5 & 2 & 4 & 8 & 16\end{array}>$ repressed 